\section{Alteration in transforming growth factor- $\beta$ receptor expression in gallbladder disease: implications of chronic cholelithiasis and chronic Salmonella typhi infection}

Yogesh D. Walawalkar1 Yatindra Vaidya, Vijayashree Nayak ${ }^{1}$

1'Department of Biological Sciences, Birla Institute of Technology and Science; 2Department of Surgery, SMRC-Hospital, Goa, India

\section{Abstract}

Gallbladder cancer prevalence is ever increasing with Salmonella typhi chronic infection being one of the predisposing factors. Altered ratios or expression of transforming growth factor- $\beta$ (TGF- $\beta$ ) receptors and changes in its function are associated with loss in anti-proliferative effects of TGF- $\beta$ and cancer progression. Using reverse transcriptase polymerase chain reaction we monitor any changes in TGF- $\beta$ receptor gene expression. We simultaneously screen for $S$. typhi within the samples. From 73 patients undergoing cholecystectomy $39-50 \%$ had significant expression $(\mathrm{P}<0.05)$ of TGF- $\beta$ receptor $(\mathrm{T} \beta \mathrm{R})$ I and T $\beta$ R-II during chronic cholelithiasis as compared to the remaining $19-23 \%$ with acute chronic cholelithiasis. There was no significant increase in T $\beta$ R-III receptor expression. Patient's positive for $S$. typhi (7/73) did not show any significant changes in expression of these receptors, thus indicating no direct relation in regulating the host TGF $\beta$-signaling pathway. Further analysis on expression of downstream Smad components revealed that patients with up-regulated TGF $\beta$ receptor expression show $>2$-fold increase in the RSmads and Co-Smads with a $>2$-fold decrease in I-Smads. Thus gain of T $\beta$ R-I and II expression in epithelial cells of the gallbladder was associated with chronic inflammatory stages of the gallbladder disease.

\section{Introduction}

Transforming growth factor- $\beta$ (TGF- $\beta$ ) plays a complex role in adult tissue homeostasis and embryonic development. 1,2 TGF- $\beta$ is also shown to have tumor suppressor and malignant activities and plays a complex role during carcinogenesis. ${ }^{3}$ The TGF- $\beta$ ligands bind to the type TGF- $\beta$ receptors which are a group of ser- ine/threonine kinases that induce the downstream Smad and other signaling pathways. The binding of the ligand to type II receptor recruits the type I receptor to form a ternary complex, indicating the importance of both receptors in signal transduction. The receptorregulated Smads (R-Smads) are phosphorylated by type I receptors and oligomerize with Smad4 (Co-Smad) which than translocate to the nucleus to regulate a variety of gene expressions. On a contrary, the inhibitory Smads block R-Smad phosphorylation and induce receptor dephosphorylation. ${ }^{2,4,5}$ The TGF- $\beta$ signal transduction pathways play a major role in human diseases. ${ }^{6}$ Altered ratios or expression of TGF- $\beta$ type I and II receptors and changes in its function are associated with loss in anti-proliferative effects of TGF- $\beta$ and cancer progression. ${ }^{7-9}$ Various factors affect the TGF- $\beta$ signaling pathway that includes disease condition, infection, genetic pre-disposition, etc. thus making it a strong marker of prognostic significance..$^{1,2}$

Chronic cholelithiasis is a frequently encountered gallbladder disease being highly prevalent in Northern region of India. ${ }^{10-12}$ The very fact that presence of such gallstones bring about alterations in molecular and histopathological characters in the gallbladder tissue, makes it a strong predisposing factor for development of gallbladder cancer. ${ }^{13}$ Also existence of $S$. typhi within gallbladder is considered to be a pre-disposing factor for gallbladder cancer. $^{14,15}$ Thus in our study we try to reveal if the presence of $S$. typhi within gallbladder of patients could possible bring about a significant change in expression of TGF- $\beta$ signaling pathway, making it a possible factor for progression towards gallbladder cancer.

\section{Materials and Methods}

\section{Clinical specimen and sample collection}

Human gallbladder tissue, bile and gallstones were obtained following laparoscopic cholecystectomy of patients suffering from chronic cholelithiasis at RG stone hospital and SMRC Hospital (Goa, India). For normal gallbladder specimens, tissue was obtained from dead bodies at Department of Forensic Science-Goa Medical College and Hospital (Goa, India). The study was approved by the institutional ethics committee. A small portion $(\sim 100 \mathrm{mg})$ of the tissue was cut and submerged in RNAlater ${ }^{\circledR}$ (Life technologies, USA) solution, and remaining of the freshly excised gallbladder tissue was immediately transported to the laboratory in sterile DMEM medium at $4^{\circ} \mathrm{C}$ for epithelial cell isolation.
Correspondence: Vijayashree Nayak, Department of Biological Sciences, Birla Institute of Technology and Science, KK Birla Goa Campus Zuarinagar, Goa 403-726, India.

Tel.: +91.0832 2580161 .

E-mail: yo.genetech@gmail.com

Key words: Gallbladder; TGF- $\beta$ receptors; Chronic cholilithiasis; Chronic infections; Cholecystectomy.

Acknowledgements: we are grateful to Birla Institute of Technology and Science (BITS), Pilani for providing financial support. We thank Dr. Ragni Gaind for providing expertise and necessary support.

Contributions: VN, analysis of data, writing and revising manuscript; YDW, design of study, collection of data and experimentation, analysis of data, writing and revising manuscript; YV, Sample collection and analysis of data.

Conflict of interest: the authors declare no potential conflict of interest.

Received for publication: 26 May 2016. Accepted for publication: 12 August 2016.

This work is licensed under a Creative Commons Attribution NonCommercial 4.0 License (CC BYNC 4.0).

(C) Copyright Y.D. Walawalkar et al., 2016

Licensee PAGEPress, Italy

Gastroenterology Insights 2016; 7:6623

doi:10.4081/gi.2016.6623

\section{Histopathological classification of gallbladder tissue}

A section of the tissue sample collected in RNAlater ${ }^{\circledR}$ was used for histological analysis as RNAlater ${ }^{\circledR}$ preserves the tissue histology. Transverse sections of the wall including mucosa were fixed in formalin, embedded in paraffin, sectioned and stained with hematoxylin and eosin (H\&E) using routine histological procedures.

\section{Detection of S. typhi DNA using PCR assay}

All the clinical specimens (gallbladder, bile and gallstone) obtained were subjected to PCR assay for detection of $S$. Typhi specific gene fragment as described in our earlier work. ${ }^{16}$ The DNA was extracted from $25-30 \mathrm{mg}$ of sample using the NucleoSpin ${ }^{\circledR}$ Tissue (MachereyNagel-GmbH \& Co. KG, Duren, Germany) Kit as per manufacturer's instructions. The template DNA was subjected to PCR amplification using primers specific to $\mathrm{H}-\mathrm{ld}$ region of flagellin gene fragment of $S$. typhi (Table 1). The expected 181bp fragment was visualized using 
1.5\% agarose gel. The fragment was eluted using QiaQuick Gel Extraction Kit (Qiagen), cloned in pGEM-T Easy vector system (Promega) and sequenced to confirm desired gene amplification.

\section{Isolation of gallbladder epithelial cells}

The isolation of gallbladder epithelial cells was performed as described by Miquel and colleagues with few modifications. ${ }^{17}$ Briefly, the isolation was carried out within $30-45$ minutes post-surgery. The mucosa was rinsed carefully with DMEM to remove any adherent mucous and bile. The tunica mucosa was placed in $0.125 \%$ collagenase solution prepared in DMEM for 15 minutes at $37^{\circ} \mathrm{C}$. The mucosa was abraded every 5 minutes using a scalpel and flushed with DMEM. The resulting cell suspension was immediately subjected to centrifugation at $1000 \mathrm{rpm}$ for five minutes. An aliquot from the cells obtained was used for characterization using immunostaining by cytokeratin 19 antibodies, and remaining epithelial cells were used for further expression analysis.

\section{RNA isolation and reverse transcriptase PCR}

Total RNA was extracted with RiboZol ${ }^{\mathrm{TM}}$ (Amresco, USA) and quantified using NanoDrop Lite spectrophotometer (Thermo Scientific, India). Reverse-Transcriptase PCR was carried out using Revert Aid First Strand cDNA Synthesis Kit (Thermo Scientific, India) and oligo $(\mathrm{dT})^{18}$ primer as per the manufacturer's protocol. For every reaction of cDNA synthesis $1 \mu \mathrm{g}$ of purified RNA was used followed by PCR amplification using specific primers to candidate genes listed in Table 1 within the linear range of amplification (35 cycles). A 10 $\mu \mathrm{L}$ aliquot of the amplified product was loaded on $1.6 \%$ agarose gel and bands obtained were analyzed using Image J 1.46r software. The normalized gene expression with a $>1.5$ fold increase and a $\mathrm{P}<0.01$ was considered to be significant.

\section{Statistical analysis}

All the values obtained are representative of at least three independent replicates with the standard mean, standard deviation, and standard error values. The statistical significance for independent variables was determined using the chi-square test with $\mathrm{P}<0.05$ considered to be significant.

\section{Results}

Classification of gallbladder tissue samples and isolating gallbladder epithelial cells: Human gallbladders were obtained from patients with gallstone disease after cholecysytectomy, followed by a routine H\&E staining that showed varying degree of chronic cholelithiasis (Figure 1c) with cholecystitis depending on the stage in which the patients were operated. In order to understand TGF- $\beta$ receptor expression specifically within the gallbladder epithelium, gallbladder epithelial cells were isolated from freshly excised human gallbladder tissue (Figure 1a) and immunos- tained using CK19 antibody (Figure 1b) which demonstrated an isolation efficiency of 85$90 \%$. The cells obtained were used for harvesting mRNA so as to determine changes in expression of desired components.

Alteration in TGF- $\beta$ receptor expression during chronic cholelithiasis: From 73 patients undergoing cholecystectomy, 39/50 showed significant over-expression $(\mathrm{P}<0.05)$ of TGF- $\beta$ receptor (T $\beta R$ )-I and T $\beta$ R-II during chronic

Table 1. Primer pairs used for this study.

\begin{tabular}{|c|c|c|c|}
\hline Gene & & Primer pairs & Product size (bp) \\
\hline$H-1 d$ & $\begin{array}{l}\text { LP } \\
\mathrm{RP}\end{array}$ & $\begin{array}{c}\text { TCGTTTGAGGATAAAAACGGTA } \\
\text { CAGTTTGAGCAACGCCAGTA }\end{array}$ & 181 \\
\hline$T \beta R I$ & $\begin{array}{l}\mathrm{LP} \\
\mathrm{RP}\end{array}$ & $\begin{array}{l}\text { GATGGGCTCTGCTTTGTCTC } \\
\text { CAAGGCCAGGTGATGACTTT }\end{array}$ & 214 \\
\hline$T \beta R I I$ & $\begin{array}{l}\mathrm{LP} \\
\mathrm{RP}\end{array}$ & $\begin{array}{l}\text { GGGGAAACAATACTGGCTGA } \\
\text { GAGCTCTTGAGGTCCCTGTG }\end{array}$ & 198 \\
\hline$T \beta R I I I$ & $\begin{array}{l}\mathrm{LP} \\
\mathrm{RP}\end{array}$ & $\begin{array}{l}\text { CCAAGATGAATGGCACACAC } \\
\text { CCATCTGGCCAACCACTACT }\end{array}$ & 151 \\
\hline Smad 2 & $\begin{array}{l}\mathrm{LP} \\
\mathrm{RP}\end{array}$ & $\begin{array}{l}\text { CGAAATGCCACGGTAGAAAT } \\
\text { CCAGAAGAGCAGCAAATTCC }\end{array}$ & 223 \\
\hline Smad 3 & $\begin{array}{l}\text { LP } \\
\text { RP }\end{array}$ & $\begin{array}{l}\text { CCCCAGAGCAATATTCCAGA } \\
\text { GGCTCGCAGTAGGTAACTGG }\end{array}$ & 173 \\
\hline Smad 4 & $\begin{array}{l}\mathrm{LP} \\
\mathrm{RP}\end{array}$ & $\begin{array}{l}\text { TCACAATGAGCTTGCATTCC } \\
\text { ACCTTTGCCTATGTGCAACC }\end{array}$ & 247 \\
\hline Smad 7 & $\begin{array}{l}\text { LP } \\
\text { RP }\end{array}$ & $\begin{array}{l}\text { GGGTTCTAGCTCTGGCTGTG } \\
\text { CAGGCTCTTACAGCCCTTTG }\end{array}$ & 358 \\
\hline
\end{tabular}

$T \beta R$, transforming growth factor $-\beta$ receptor.
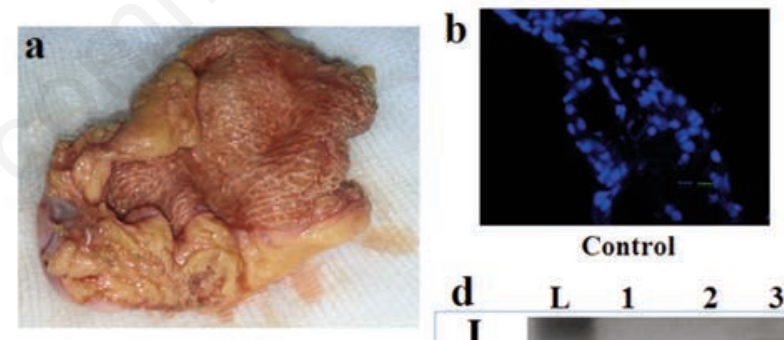

Control
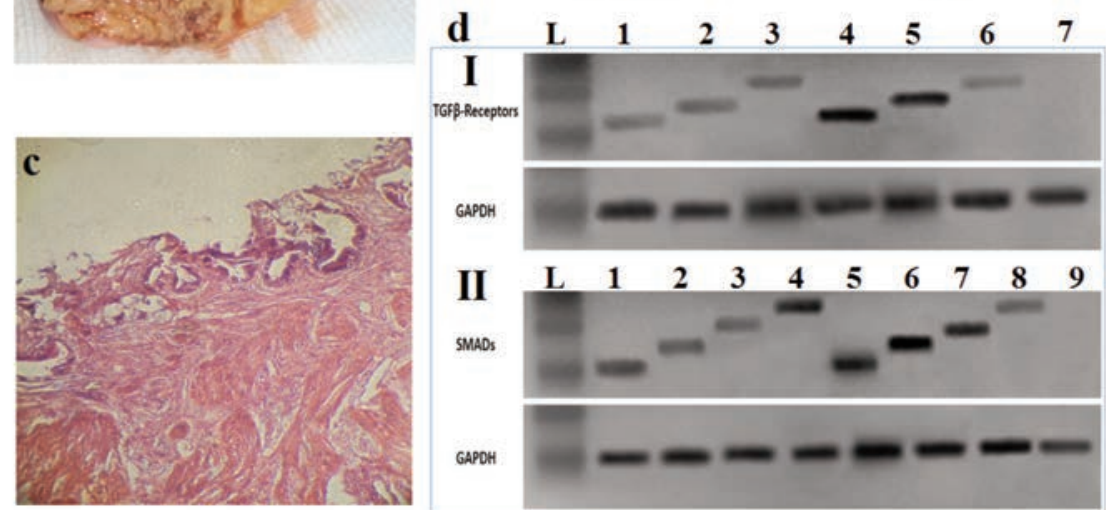

GAPOH

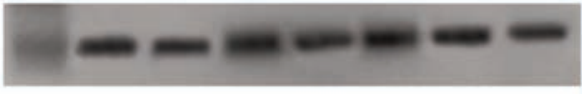

II

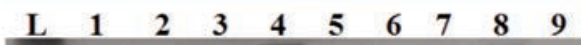

SMAD:

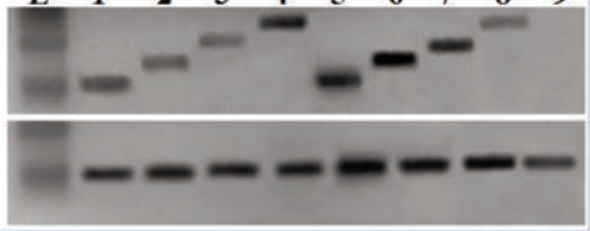

Figure 1. Expression of transforming growth factor- $\beta$ (TGF- $\beta$ )/Smad's in gallbladder epithelium. a) Gallbladder obtained following cholecystectomy. b) gallbladder epithelial cells isolated from gallbladder tissue in vitro. c) Histopathological characterisation of gallbladder tissue obtained from patients. d) Reverse transcriptase polymerase chain reaction assay for detection of changes in candidate gene expression. L: ladder; 1d (I): Lane $1,2,3$ and Lane 4, 5, 6 represent TGF- $\beta$ receptor I, II, III respectively for d (I); $1 \mathrm{~d}$ (II): Lane 1, 2, 3, 4 and Lane 5, 6, 7, 8 represent SMAD 2, 3, 4 and 7 respectively. 
cholelithiasis as compared to 19/23 with acute chronic cholelithiasis (Figure 2a, b, c). Overall $79.45 \%$ of the patients had up-regulated ( $>1.5$ fold increase) TGF- $\beta$ receptor I and II expression in their gallbladder epithelium. There was no significant increase in T $\beta$ R-III receptor expression observed in epithelium of any patients.

Effect of chronic S. Typhi persistence on TGF- $\beta$ receptor signaling in gallbladder epithelium: Upon molecular screening of clinical samples (gallbladder tissue, bile and gallstones) $9.59 \%$ (7/73) of the patients showed positive results for the presence of $S$. Typhi DNA within the gallbladder of patients suffering from gallbladder disease. Interestingly, none of these patients showed any significant effect on the TGF- $\beta$ receptor gene expression with similar fold changes as seen in patients without any chronic S. Typhi infection.

Regulation of the downstream-Smad signaling axis: It was observed that patients with upregulated levels of TGF $\beta$ receptors I and II had significantly altered expression levels of downstream Smad components. This includes the RSmad's (Smad-2 and 3), Co-Smad (Smad 4) and the I-Smad (Smad 7). The R-and CoSmads had lower expression levels in normal samples with higher levels of the I-Smads. In case of patients suffering from gallbladder disease, we observe that there was a nearly 2 -fold increase in the expression of TGF- $\beta$ receptor I and II with a $\sim 2$-fold decrease in the TGF- $\beta$ receptor III (Figure 2d). Thus during chronic cholelithiasis the gallbladder epithelium shows activation of the Smad-dependent TGF$\beta$ signalling axis.

\section{Discussion}

The TGF- $\beta$ growth factor regulates growth and differentiation in various cell types and tissues, and plays a major role in human diseases. They are shown to play a dual role of tumor suppression and cancer metastasis., ${ }^{2,3}$ These primarily function via the TGF- $\beta$ receptors and thus any alterations in the TGF- $\beta$ receptors, may it be epigenetic changes or genetic modification, alters the TFG- $\beta$ signaling axis. 7,8 Thus monitoring expression of these receptors may be of prognostic significance during progression towards cancer. ${ }^{18,19}$ In this study we try to analyze the expression levels of these receptors in early stages of gallbladder disease and even reveal the alteration in expression of the downstream Smad signaling components. We also see if the present of chronically persisting typhi within the gallbladder could significantly bring about any changes in these components of the signal transduction pathway. As observed, S S. typhi did not significantly alter the receptor expression or the Smad components indicating that the fold changes were due to the diseased state of the gallbladder. Though, S. typhi is shown to persist within the gallbladder even in earlier
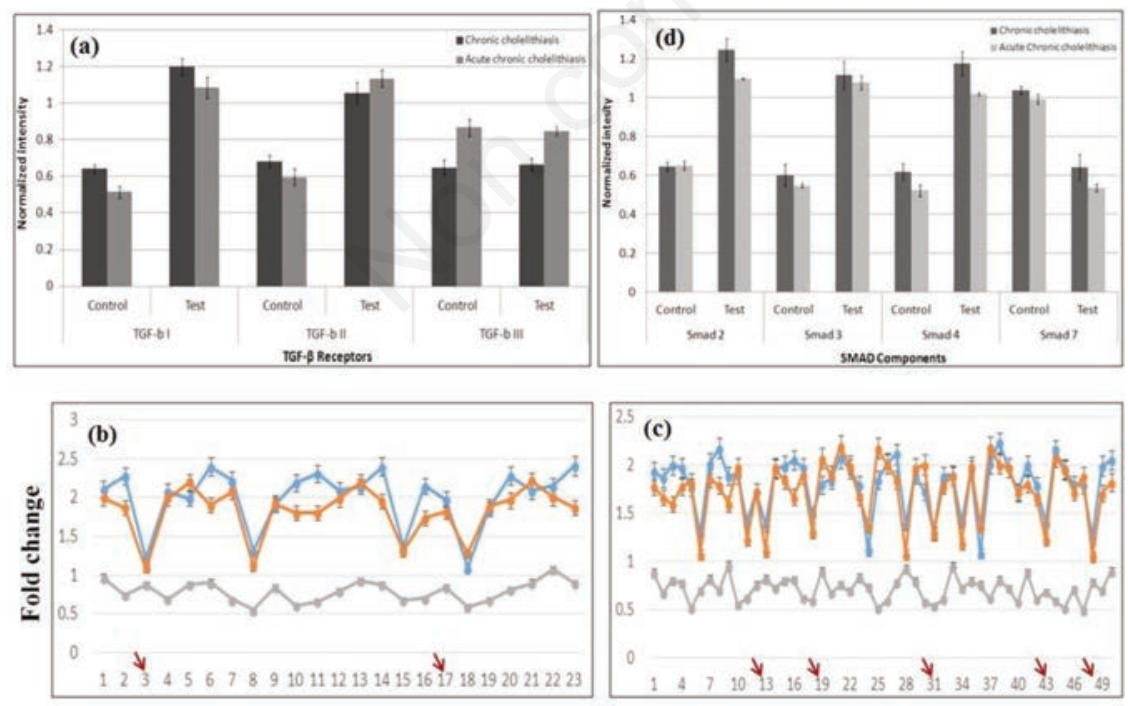

Patients

Figure 2. Changes in expression of transforming growth factor- $\beta$ receptor $(T \beta R)$ in given set of population. a) Changes in gene expression of T $\beta$ R I, II, III in gallbladder epithillium of patients suffering from chronic cholelithiasis. Data is representative of means of at least three biological replicates with ${ }^{*} P<0.05$. b) and c) $T \beta R$ expression in patients undergoing cholecystectomy. Red arrow indicates patients detected with Salmonella Typhi in their gallbladder. d) Changes in gene expression of Smad components.

literature, ${ }^{14-16}$ its role in significantly regulating the host to progress towards cancer needs to be understood. Thus gain of TGF- $\beta$ receptor I and II expression in epithelial cells of the gallbladder was associated with chronic inflammatory stages of the gallbladder disease.

\section{Conclusions}

Both chronic cholelithiasis and S. typhi are considered to be pre-disposing factors for gallbladder cancers. We conclude from our study that chronic cholelithiasis is majorly involved in bringing about the changes in expression of the TGF- $\beta /$ Smad signaling components in the host epithelium. Though $S$. typhi chronically persists within the gallbladder, their low numbers or Viable but non culturable state may not significantly alter the host mechanisms to cause cancer. This needs further investigation and analysis.

\section{References}

1. Massagué J. TGF- $\beta$ signal transduction. Annu Rev Biochem 1998;67:753-91.

2. Mehra A, Wrana JL. TGF- $\beta$ and the Smad signal transduction pathway. Biochem Cell Biol 2002;80:605-22.

3. Nagaraj NS, Datta PK. Targeting the transforming growth factor- $\beta$ signaling pathway in human cancer. Expert Opin Investig Drugs 2010;19:77-91.

4. Derynck R, Zhang YE. Smad-dependent and Smad-in- dependent pathways in TGFbeta family signalling. Nature 2003;425:577-84.

5. Chen YG. Endocytic regulation of TGF-beta signaling. Cell Res 2009;19:58-70.

6. Harradine KA, Akhurst RJ. Mutations of TGF-beta signaling molecules in human disease. Ann Med 2006;38:403-14.

7. Antony ML, Nair R, Sebastian P, Karunagaran D. Changes in expression, and/or mutations in TGF-beta receptors (TGF-beta RI and TGF-beta RII) and Smad 4 in human ovarian tumors. J Cancer Res Clin Oncol 2010;136:351-61.

8. Rojas A, Padidam M, Cress D, Grady WM. TGF-beta receptor levels regulate the specificity of signaling pathway activation and biological effects of TGF-beta. Biochim Biophys Acta 2009;1793:1165-73.

9. Huang F, Chen YG. Regulation of TGF- $\beta$ receptor activity. Cell Biosci 2012;2:9.

10. Stinton LM, Shaffer EA. Epidemiology of gallbladder disease: cholelithiasis and cancer. Gut Liver 2012;6:172-87.

11. Misra S, Chaturvedi A, Misra NC, Sharma ID. Carcinoma of the gallbladder. Lancet 
Oncol 2003;4:167-76.

12. Tewari M, Mishra RR, Shukla HS. Salmonella typhi and gallbladder cancer: report from an endemic region. Hepatobiliary Pancreat Dis Int 2010;9:52430.

13. Wistuba II, Gazdar AF. Gallbladder cancer: lessons from a rare tumour. Nat Rev Cancer 2004;4:695-706.

14. Gonzalez-Escobedo G, Marshall JM, Gunn JS. Chronic and acute infection of the gall bladder by Salmonella Typhi: understanding the carrier state. Nat Rev Microbiol
2011:9:9-14.

15. Gonzalez-Escobedo G, Gunn JS. Gallbladder epithelium as a niche for chronic Salmonella carriage. Infect Immun 2013;81:2920-30.

16. Walawalkar YD, Gaind R, Nayak V. Study on Salmonella Typhi occurrence in gallbladder of patients suffering from chronic cholelithiasis - a predisposing factor for carcinoma of gallbladder. Diagn Microbiol Infect Dis 2013;77:69-73.

17. Miquel JF, Moreno M, Amigo L, et al. Expression and regulation of scavenger receptor class B type I (SR-BI) in gall bladder epithelium. Gut 2003;52:1017-24.

18. Buck MB, Fritz P, Dippon J, et al. Prognostic significance of transforming growth factor beta receptor II in estrogen receptor-negative breast cancer patients. Clin Cancer Res 2004;10:491-8.

19. Koumoundourou D, Kassimatis T, Zolota V, et al. Prognostic significance of TGFbeta-1 and $\mathrm{pSmad} 2 / 3$ in breast cancer patients with T1-2,N0 tumours. Anticancer Res 2007;27:2613-20. 